\title{
Article \\ Production of Highly Porous Biochar Materials from Spent Mushroom Composts
}

\author{
Wen-Shing Chen ${ }^{1}$, Wen-Tien Tsai ${ }^{2} * \mathbb{D}$, Yu-Quan Lin ${ }^{2}$, Chi-Hung Tsai ${ }^{3}$ and Yao-Tsung Chang ${ }^{4}$ \\ 1 Department of Chemical and Materials Engineering, National Yunlin University of Science and Technology, \\ Yunlin 640, Taiwan; chenwen@yuntech.edu.tw \\ 2 Graduate Institute of Bioresources, National Pingtung University of Science and Technology, \\ Pingtung 912, Taiwan; wsx55222525@gmail.com \\ 3 Department of Resources Engineering, National Cheng Kung University, Tainan 701, Taiwan; \\ ap29fp@gmail.com \\ 4 Kaohsiung District Agricultural Research and Extension Station, Council of Agriculture, \\ Pingtung 908, Taiwan; ytc@mail.kdais.gov.tw \\ * Correspondence: wttsai@mail.npust.edu.tw; Tel.: +886-8-7703202
}

check for updates

Citation: Chen, W.-S.; Tsai, W.-T.; Lin, Y.-Q.; Tsai, C.-H.; Chang, Y.-T.

Production of Highly Porous Biochar

Materials from Spent Mushroom

Composts. Horticulturae 2022, 8, 46.

https://doi.org/10.3390/

horticulturae 8010046

Academic Editor: Agnieszka Jasińska

Received: 7 December 2021

Accepted: 29 December 2021

Published: 4 January 2022

Publisher's Note: MDPI stays neutral with regard to jurisdictional claims in published maps and institutional affiliations.

Copyright: (C) 2022 by the authors. Licensee MDPI, Basel, Switzerland. This article is an open access article distributed under the terms and conditions of the Creative Commons Attribution (CC BY) license (https:// creativecommons.org/licenses/by/ $4.0 /)$.

\begin{abstract}
The edible mushroom industry has grown significantly in recent years due to the dietary change and the demand for heathy food. However, the spent mushroom compost (SMC) will be produced in large quantities after the harvest, thus forming an agricultural waste requiring proper management other than dumping or burning. In this work, two types of SMCs with the cultivation of shiitake fungus (SF) and black fungus (BF) were converted into porous biochar products (a series of SMC-SF-BC and SMC-BF-BC) at higher pyrolysis temperatures (i.e., 400, 600 and $800{ }^{\circ} \mathrm{C}$ ) based on their thermochemical characteristics, using thermogravimetric analysis (TGA). The pore and chemical properties of the resulting products, including surface area, pore volume, average pore size, scanning electron microscopy (SEM), energy dispersive X-ray spectroscopy (EDS) and Fourier Transform infrared spectroscopy (FTIR), were studied to correlate them with the most important process parameter. The results showed that the pore properties of the biochar products indicated a significant increase with the increase in the pyrolysis temperature from 400 to $600{ }^{\circ} \mathrm{C}$. The data on the maximal Brunauer-Emmett-Teller (BET) surface area for the biochar products produced at $800{ }^{\circ} \mathrm{C}$ (i.e., SMC-SF-BC-800 and SMC-BF-BC-800) were found to be 312.5 and $280.9 \mathrm{~m}^{2} / \mathrm{g}$, respectively. Based on the EDS and FTIR, plenty of oxygen-containing functional groups were found on the surface of the resulting biochar products.
\end{abstract}

Keywords: spent mushroom compost; thermogravimetric analysis; biochar; pore property; chemical composition

\section{Introduction}

The global production of edible mushrooms has grown more and more significant in recent years as a result of the product being recognized as a healthy and organic food [1] Most of the mushroom cultivation used compost as a substrate, which is comprised of lignocellulosic components like rice straw, corncob, saw dust and wood chips [2]. However, most of these substrates will become spent mushroom compost (SMC) after harvesting. According to the report [3], approximately $5 \mathrm{~kg}$ of SMC will be generated during the production of $1 \mathrm{~kg}$ edible mushroom. In Taiwan, annual SMC generation amounted 105-225 thousand metric tons since 2010, as shown in Figure 1 [4]. Although these agricultural residues can be mostly transformed into compost materials [4], some were dumped or stacked to the fields in Taiwan, thus causing environmental sanitation (odor) and plastic bag disposal problems [5]. In order to reach zero waste management, the approaches of SMC valorization were recently reviewed to utilize it as a valuable bioresource for producing 
value-added products/by-products and applications, for example, as a biochar adsorbent or soil amendment $[2,6,7]$.

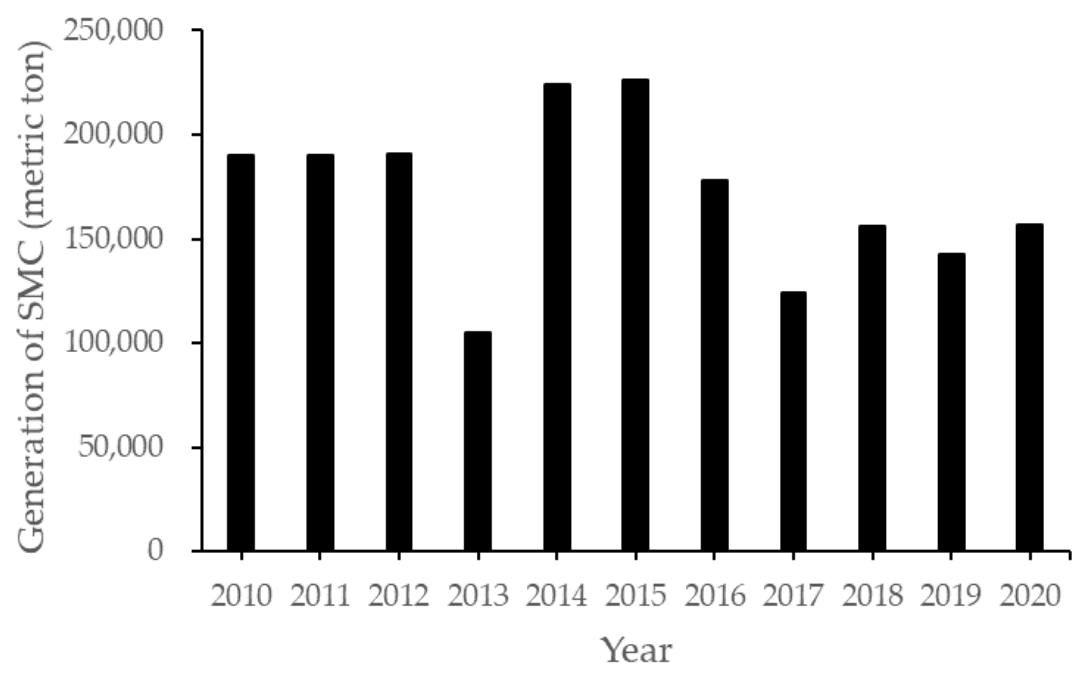

Figure 1. Reported amounts of spemt mushroom compost (SMC) generation in Taiwan since 2010 [4].

Biochar is a carbon-rich material which is often produced from lignocellulosic biomass (e.g., crop or wood residues) at the proper pyrolysis conditions in an oxygen-limited atmosphere [8]. Due to its porous and chemical properties, biochar can be used to improve the environmental quality and agricultural soils in several aspects [9]. Furthermore, biochar may be carbon-negative, thus sequestrating the release of carbon dioxide into the atmosphere and also removing it from the atmosphere. In order to reuse SMC as an available precursor for producing biochar [10] and other derived products [11], this lignocellulosic residue has been recently studied to produce porous carbon materials for adsorbing a variety of pollutants in aqueous solutions, including inorganic compounds (e.g., heavy metals) [3,12-17], organic compounds [18,19] and other pollutants [20-22]. Biochar can also conserve nutrients in soils [23], mitigate the emissions of greenhouse gases [24,25], and can be produced to biomass fuels [26]. It was reported that the pore properties of biomass-based biochar products were highly dependent on the pyrolysis temperature because the turbostratic structure can be formed at higher temperatures [27].

In view of the published literature describe above, there are few studies on the production of SMC-based biochar at higher temperature (e.g., $800{ }^{\circ} \mathrm{C}$ ). Therefore, this work focused on investigating the two SMCs (i.e., shiitake fungus (SF) and black fungus (BF)) for converting them into porous biochar products (a series of SMC-SF-BC and SMC-BF-BC) at different pyrolysis temperatures (i.e., 400, 600 and $800{ }^{\circ} \mathrm{C}$ ) for specified residence time (i.e., $20 \mathrm{~min}$ ). The pore and chemical properties of the resulting SMC-BC products, including surface area, pore volume, average pore size, scanning electron microscopy (SEM), energy dispersive X-ray spectroscopy (EDS) and Fourier Transform infrared spectroscopy (FTIR), were obtained to correlate them with the most important process parameter (i.e., pyrolysis temperature).

\section{Materials and Methods}

\subsection{Material}

The SMC feedstocks, including SF and BF, were provided by an agricultural research station (Pingtung County, Taiwan). The as-received SMC mainly contains wood chips, plastic bags and residual cultivation soil. It was first disassembled to remove external plastic coating and internal non-lignocellulosic component (i.e., cultivation soil). Wood chips are often made from broadleaf tree like Taiwan Acacia and Formosan sweet gum. The lignocellulosic component was shredded and then sieved to a target sample in the range of mesh sieve no. $20(0.841 \mathrm{~mm})$ to mesh sieve no. $40(0.420 \mathrm{~mm})$. Prior to the analyses and 
pyrolysis experiments, the sieved SMC sample was placed into a circulation oven at about $105^{\circ} \mathrm{C}$.

\subsection{Thermochemical Analysis of Spent Mushroom Compost}

In order to give the operation conditions in the pyrolysis experiments, the analyzer (TGA-51; Shimadzu Co., Tokyo, Japan) was performed to collect the variations on the thermogravimetric analysis (TGA) of the dried SMC samples. Around $0.2 \mathrm{~g}$ of the SMC sample was externally heated up to $1000{ }^{\circ} \mathrm{C}$ at various heating rates (i.e., 5, 10, 15 and $20{ }^{\circ} \mathrm{C} / \mathrm{min}$ ) under the nitrogen $\left(\mathrm{N}_{2}\right)$ atmosphere by flowing $50 \mathrm{~cm}^{3} / \mathrm{min}$. During the TGA measurements, the curves of TGA and its derivative thermogravimetry (DTG) were plotted by using the normalize weight of SMC sample. On the other hand, the proximate properties (i.e., mass fractions of volatile matter, ash and fixed carbon) of the dried SMC samples were determined by using the Standard Test Method of the American Society for Testing and Materials (ASTM) (i.e., D-3172). Furthermore, ultimate analysis (i.e., the mass percentages of $\mathrm{C}, \mathrm{H}, \mathrm{N}, \mathrm{S}$ and $\mathrm{S}$ ) and elements in ash (i.e., $\mathrm{Al}, \mathrm{As}, \mathrm{Ba}, \mathrm{Ca}, \mathrm{Cd}, \mathrm{Co}, \mathrm{Cr}, \mathrm{Cu}$, $\mathrm{Fe}, \mathrm{K}, \mathrm{Mg}, \mathrm{Mn}, \mathrm{Na}, \mathrm{Ni}, \mathrm{P}, \mathrm{Pb}, \mathrm{Si}, \mathrm{Sr}, \mathrm{Ti}$ and $\mathrm{Zn}$ ) of the SMC samples were measured by the elemental analyzer (EA) and inductively coupled plasma-optical emission spectrometer (ICP-OES), respectively [28]. The contents of ultimate analysis are highly correlated with their calorific values, which were determined by an isoperibol oxygen bomb calorimeter (CALORIMETER ASSY 6200; Parr Instrument Co., Moline, IL, USA).

\subsection{Prolysis Experiments}

In this work, the pyrolysis experiments were operated at above $400{ }^{\circ} \mathrm{C}$ due to the features of lignocellulosic feedstocks. The pyrolysis experiments were performed at higher pyrolysis temperatures (i.e., 400, 600 and $800^{\circ} \mathrm{C}$ ) under a specified residence time (i.e., $20 \mathrm{~min}$ ). During the pyrolysis experiment, about $3 \mathrm{~g}$ of the SMC sample was fed into a vertical pyrolysis furnace, and then heated at a ramp rate of around $10^{\circ} \mathrm{C} / \mathrm{min}$ under the purge gas (500 $\mathrm{cm}^{3} / \mathrm{min}$ by nitrogen) $[28,29]$. The yield of the resulting biochar by weight percentage $(\mathrm{wt} \%)$ was calculated from the ratio of biochar mass to SMC mass by using the following equation:

$$
\text { Yield }(w \mathrm{t} \%)=(\text { biochar mass } / \text { SMC mass }) \times 100 \%
$$

To facilitate the data comparison, the SMC-based biochar products were coded by a series of SMC-SF-BC-temperature and SMC-BF-BC-temperature.

\subsection{Physicochemical Properties of Resulting Biochar}

In order to study the relationship between the physical properties of resulting biochar products and the pyrolysis temperature, the surface area and porosity analyzer (ASAP 2020; Micromeritics Co., Norcross, GA, USA) was performed to obtain their pore properties, including surface area, pore volume and pore size distribution [30]. In this work, the calculations of specific surface area were based on different principles or models, including single-point, Brunauer-Emmett-Teller (BET), Langmuir and $t$-plot methods. Among the surface area data, the BET surface area may be the most important one, which was obtained from the relative pressure range (0.05-0.30). Regarding the pore volume, the total pore volume could be often adopted to act as the adsorption capacity potential. In this work, it was obtained by calculating the nitrogen liquid adsorption volume saturated at a relative pressure of ca. 0.995 [30]. Based on the $t$-plot method, the values of micropore area and micropore volume can be calculated from the Halsey equation [30]. Based on the classification by the International Union of Pure and Applied Chemistry (IUPAC) [30], micropores and mesopore were defined as pore diameter (or pore width) of less than $2 \mathrm{~nm}$ and 2-50 nm, respectively. In addition, the pore size distributions of the biochar products were further plotted by using the Barrett-Joyner-Halenda (BJH) method [30], which was adopted to calculate them in the main range of mesopores.

In order to observe their textural morphologies, the typical SMC-BC products must be first coated by a conductive gold layer in an ion sputter (E1010; Hitachi Co., Tokyo, 
Japan) prior to the SEM (S-3000N; Hitachi Co., Tokyo, Japan) observations. By applying an accelerating potential of $15.0 \mathrm{kV}$ (electron beam) in a vacuum chamber, it was performed to the specimen surface during the SEM analysis. In addition, the EDS system $(7021-\mathrm{H}$; HORIBA Co., Kyoto, Japan) was also used to quantify the elemental compositions during the SEM analysis. Furthermore, the surfaces of the SMC-BC products were scanned by the FTIR instrument (FT/IR-4600; JASCO Co., Tokyo, Japan) to determine the functional groups. During the FTIR analysis, the ground SMC-BC sample was premixed with powered potassium bromide ( $\mathrm{KBr}$, IR grade) in an agate mortar, forming around $1 \mathrm{wt} \%$ biochar. To make a disc-shaped sample for the FTIR analysis, the finely uniform mixture was pressed by using a hydraulic machine. The transmission spectra were y scanned with a resolution of $4 \mathrm{~cm}^{-1}$ in the range of $4000-400 \mathrm{~cm}^{-1}$.

\section{Results}

\subsection{Thermochemical Characterization of Spemt Mushroom Compost (SMC)}

The thermochemical characteristics of biomass greatly influence the performance of a pyrolysis system for producing biochar with different pore structures [8]. Table 1 listed the data on the proximate properties, organic elements and calorific values for the dried SMC samples (i.e., SF and BF). It showed that the measured data were close to those of other biomass residues [31]. Based on the data in Table 1, these SMC samples had relatively high calorific values ( $>20 \mathrm{MJ} / \mathrm{kg}$, dry basis) and combustible values (76-77 $\mathrm{wt} \%)$, and also indicated no significant difference between them, reflecting their carbon contents ( $45.3 \mathrm{wt} \%)$ and low ash contents $(3.5 \mathrm{wt} \%)$. On the other hand, the contents of nitrogen $(\mathrm{N})$ and sulfur (S) for the SMC samples indicated relatively high values as compared to those for biomass fuels [31]. This difference could be attributed to residual sulfate/nitrate fertilizers in the SMC. Therefore, sulfur oxides and nitrogen oxides may be emitted from the combustion of SMC without control system installed. Based on the analytical results by the ICP-OES, it further indicated that the contents of dominant elements in the SMC's ash were calcium $(\mathrm{Ca})$, potassium $(\mathrm{K})$, silica $(\mathrm{Si})$, magnesium $(\mathrm{Mg})$, iron $(\mathrm{Fe})$, aluminum $(\mathrm{Al})$ and sodium $(\mathrm{Na})$, which could be present in the forms of oxides and/or carbonates [31].

Table 1. Thermochemical properties of spent mushroom composts (SMC).

\begin{tabular}{|c|c|c|}
\hline \multirow{2}{*}{ Properties $^{a}$} & \multicolumn{2}{|c|}{ Value } \\
\hline & SMC-SF & SMC-BF \\
\hline \multicolumn{3}{|l|}{ Proximate analysis $b$} \\
\hline Ash $(w t \%)$ & $3.53 \pm 0.78$ & $3.51 \pm 0.60$ \\
\hline Combustibles (wt\%) & $77.01 \pm 0.60$ & $76.36 \pm 16.64$ \\
\hline Fixed carbon ${ }^{c}(w t \%)$ & $19.46 \pm 0.65$ & $20.13 \pm 16.82$ \\
\hline \multicolumn{3}{|l|}{ Ultimate analysis $\mathrm{d}$} \\
\hline Carbon $(\mathrm{wt} \%)$ & $45.43 \pm 0.11$ & $45.29 \pm 0.01$ \\
\hline Hydrogen $(w \mathrm{t} \%)$ & $6.25 \pm 0.07$ & $6.43 \pm 0.06$ \\
\hline Oxygen $(w t \%)$ & $46.58 \pm 0.35$ & $47.02 \pm 0.01$ \\
\hline Nitrogen $(w t \%)$ & $0.64 \pm 0.04$ & $0.57 \pm 0.16$ \\
\hline Sulfur $(w t \%)$ & $0.51 \pm 0.01$ & $0.57 \pm 0.03$ \\
\hline Calorific value $\left(\mathrm{MJ} \mathrm{kg}^{-1}\right) \mathrm{b}$ & $22.10 \pm 1.60$ & $20.53 \pm 0.09$ \\
\hline
\end{tabular}

${ }^{a}$ On a dry basis. ${ }^{b}$ In triplicate. ${ }^{c}$ By difference. ${ }^{d}$ In duplicate.

In general, the weight loss of lignocellulosic biomass, identified from the TGA/DTG curves, includes the following three regions [32]: loss of moisture (from room temperature to around $\left.200{ }^{\circ} \mathrm{C}\right)$, loss of organic carbon $\left(200-500{ }^{\circ} \mathrm{C}\right)$ and loss of small amounts of cellulose/lignin and carbonates/other inorganics (e.g., chlorides) in a range of 500-1000 ${ }^{\circ} \mathrm{C}$. Figure 2 shows the TGA/DTG curves for the SMC samples (i.e., SF and BF) at various heating rates. It can be seen that the significant mass loss occurred in a range of $250-450{ }^{\circ} \mathrm{C}$, indicating the thermal degradation of lignocellulosic constituents. Furthermore, the shoulder in the left side of the most significant peak at a temperature of about $300-330{ }^{\circ} \mathrm{C}$ should 
refer to as the degradation of hemicellulose and less parts of cellulose/lignin because the former may be the most labile components among the organic constituents (i.e., hemicellulose, cellulose and lignin) [8,32]. It should be noted that the complex reactions (e.g., dehydration, cracking, decarboxylation, condensation) involve depolymerization and scission during the most rigorous stage of pyrolysis. The formed products often include non-condensable gases (e.g., $\mathrm{CO}, \mathrm{CO}_{2}, \mathrm{CH}_{4}, \mathrm{H}_{2}$ ), condensable gases or tar (e.g., $\mathrm{H}_{2} \mathrm{O}$, formic acid, acetic acid, phenols and other organics) and char. In the final pyrolysis stage at above $400{ }^{\circ} \mathrm{C}$, it should be attributable to the thermal decomposition of inorganic components (or minerals) with low melting/calcination points, and fewer parts of cellulose/lignin with rigid structures. Based on the results from the TGA/DTG curves (Figure 2), the pyrolysis conditions were designed in the range of $400-800{ }^{\circ} \mathrm{C}$ for producing porous biochar products from the SMC, where more cellulose/lignin components will be carbonized to form the carbon-rich products.

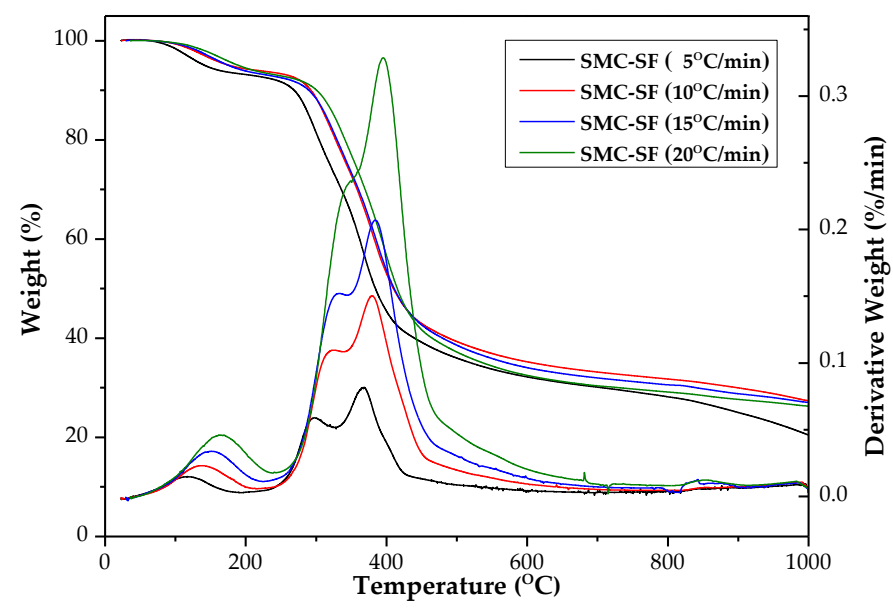

(a) SMC-SF

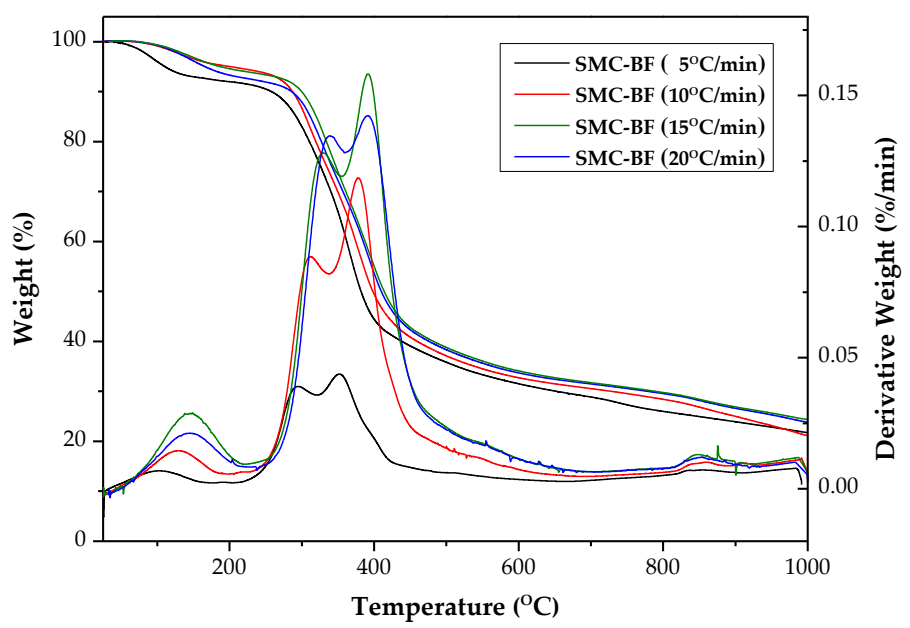

(b) SMC-BF

Figure 2. TGA/ DTG curves of (a) SMC- shiitake fungus (SMC-SF) and (b) SMC-black fungus (SMC-BF) at various heating rates $\left(5,10,15\right.$ and $\left.20^{\circ} \mathrm{C} / \mathrm{min}\right)$.

\subsection{Pore Properties of Resulting Biochar}

Before discussing the pore properties of the resulting biochar products from SMC-SF and SMC-BF, the biochar yields expectedly indicated a decreasing trend as the pyrolysis temperature increased from 400 to $800{ }^{\circ} \mathrm{C}$. In the cases of SMC-SF/SMC-BF, their biochar yields were $34.3 / 34.3 \mathrm{wt} \%, 27.0 / 27.6 \mathrm{wt} \%$, and $21.8 / 22.0 \mathrm{wt} \%$ at 400,600 and $800{ }^{\circ} \mathrm{C}$, 
respectively. These results were consistent with their similar thermochemical characteristics, as listed in Table 1.

In the present study, the pore properties of the biochar products (i.e., SMC-SF-BC and SMC-BF-BC) were based on the standard method by nitrogen adsorption-desorption isotherms at $-196{ }^{\circ} \mathrm{C}$. Tables 2 and 3 listed the main pore properties of the resulting biochar products prepared at 400, 600 and $800^{\circ} \mathrm{C}$ from SMC-SF and SMC-BF, respectively. Obviously, it showed that the consistent variations on the pore properties of the resulting biochar products as a function of pyrolysis temperature $\left(400-800{ }^{\circ} \mathrm{C}\right)$. When the pyrolysis temperature increased from 400 to $800^{\circ} \mathrm{C}$, more pyrogenic amorphous biochar was produced [27], thus forming higher pore properties due to the enhanced charring intensity. More significantly, the pore properties of the biochar products produced in this work were higher than those by other studies [3,12-22].

Table 2. Pore properties of biochar (BC) products prepared from SMC-SF at $400-800{ }^{\circ} \mathrm{C}$.

\begin{tabular}{lccc}
\hline Property & SMC-SF-BC-400 & SMC-SF- BC-600 & SMC-SF- BC-800 \\
\hline Single point surface area $\left(\mathrm{m}^{2} \mathrm{~g}^{-1}\right)^{\mathrm{a}}$ & 3.2 & 158.8 & 318.1 \\
BET surface area $\left(\mathrm{m}^{2} \mathrm{~g}^{-1}\right)^{\mathrm{b}}$ & 3.4 & 156.1 & 312.4 \\
Langmuir surface area $\left(\mathrm{m}^{2} \mathrm{~g}^{-1}\right)$ & 5.6 & 231.2 & 463.3 \\
Micropore surface area $\left(\mathrm{m}^{2} \mathrm{~g}^{-1}\right)^{\mathrm{c}}$ & $-\mathrm{g}$ & 127.2 & 255.0 \\
External surface area $\left(\mathrm{m}^{2} \mathrm{~g}^{-1}\right)^{\mathrm{d}}$ & 4.1 & 28.9 & 57.4 \\
Total pore volume $\left(\mathrm{cm}^{3} \mathrm{~g}^{-1}\right)^{\mathrm{e}}$ & 0.0093 & 0.0948 & 0.1833 \\
Micropore volume $\left(\mathrm{cm}^{3} \mathrm{~g}^{-1}\right)^{\mathrm{c}}$ & - & 0.0672 & 0.1343 \\
Pore diameter $(\mathrm{nm})^{\mathrm{f}}$ & 10.91 & 2.43 & 2.35
\end{tabular}

a Obtained at relative pressure $\left(\mathrm{P} / \mathrm{P}_{0}\right)$ of ca. $0.30 .{ }^{\mathrm{b}}$ Calculated in the relative pressure range from 0.05 to 0.30 .

${ }^{\mathrm{c}}$ Obtained by $t$-plot method. ${ }^{\mathrm{d}}$ Obtained by subtracting micropore surface area from BET surface area. ${ }^{\mathrm{e}}$ Obtained at relative pressure $\left(\mathrm{P} / \mathrm{P}_{0}\right)$ of ca. $0.99 .{ }^{\mathrm{f}}$ Obtained from the values of BET surface area and total pore volume. g Not available.

Table 3. Pore properties of biochar (BC) products prepared from SMC-BF at $400-800{ }^{\circ} \mathrm{C}$.

\begin{tabular}{lccc}
\hline Property & SMC-BF- BC-400 & SMC-BF- BC-600 & SMC-BF- BC-800 \\
\hline Single point surface area $\left(\mathrm{m}^{2} \mathrm{~g}^{-1}\right)^{\mathrm{a}}$ & 3.8 & 118.4 & 285.5 \\
BET surface area $\left(\mathrm{m}^{2} \mathrm{~g}^{-1}\right)^{\mathrm{b}}$ & 3.9 & 116.2 & 280.9 \\
Langmuir surface area $\left(\mathrm{m}^{2} \mathrm{~g}^{-1}\right)$ & 6.2 & 17.6 & 416.9 \\
Micropore surface area $\left(\mathrm{m}^{2} \mathrm{~g}^{-1}\right)^{\mathrm{c}}$ & 0.1 & 93.2 & 220.8 \\
External surface area $\left(\mathrm{m}^{2} \mathrm{~g}^{-1}\right)^{\mathrm{d}}$ & 3.8 & 23.0 & 60.1 \\
Total pore volume $\left(\mathrm{cm}^{3} \mathrm{~g}^{-1}\right)^{\mathrm{e}}$ & 0.0088 & 0.0761 & 0.1715 \\
Micropore volume $\left(\mathrm{cm}^{3} \mathrm{~g}^{-1}\right)^{\mathrm{c}}$ & 0.0001 & 0.0493 & 0.1164 \\
Pore diameter $(\mathrm{nm})^{\mathrm{f}}$ & 8.99 & 2.62 & 2.43
\end{tabular}

a Obtained at relative pressure $\left(\mathrm{P} / \mathrm{P}_{0}\right)$ of ca. $0.30 .{ }^{\mathrm{b}}$ Calculated in the relative pressure range from 0.05 to 0.30 ${ }^{\mathrm{c}}$ Obtained by $t$-plot method. ${ }^{\mathrm{d}}$ Obtained by subtracting micropore surface area from BET surface area. ${ }^{\mathrm{e}}$ Obtained at relative pressure $\left(\mathrm{P} / \mathrm{P}_{0}\right)$ of ca. $0.99 .{ }^{\mathrm{f}}$ Obtained from the values of BET surface area and total pore volume.

The pore properties of the resulting biochar products (i.e., SMC-SF-BC and SMC-BFBC) were derived from their $\mathrm{N}_{2}$ adsorption-desorption isotherms, as shown in Figure 3. Due to the adsorption filling by nitrogen adsorbate into micropores, the high uptakes were observed at relatively relative pressures, which reflects the Type-I isotherms according to the IUPAC classification [30]. However, the SMC-BC products produced at higher pyrolysis temperatures displayed the hysteresis loop, which was indicative of mesoporosity by the Type-VI isotherms. Accordingly, the resulting biochar products contain pore sizes over a wide range of micropores and mesopores. Using the $\mathrm{BJH}$ method [30], the data on the $\mathrm{N}_{2}$ adsorption-desorption isotherms can be further converted into their pore size distributions, as depicted in Figure 4. From the Figures 3 and 4, they were highly related to those in Tables 2 and 3. The differences between the pore properties of SMC-SF-BC and SMC-BF-BC products were also slight. 


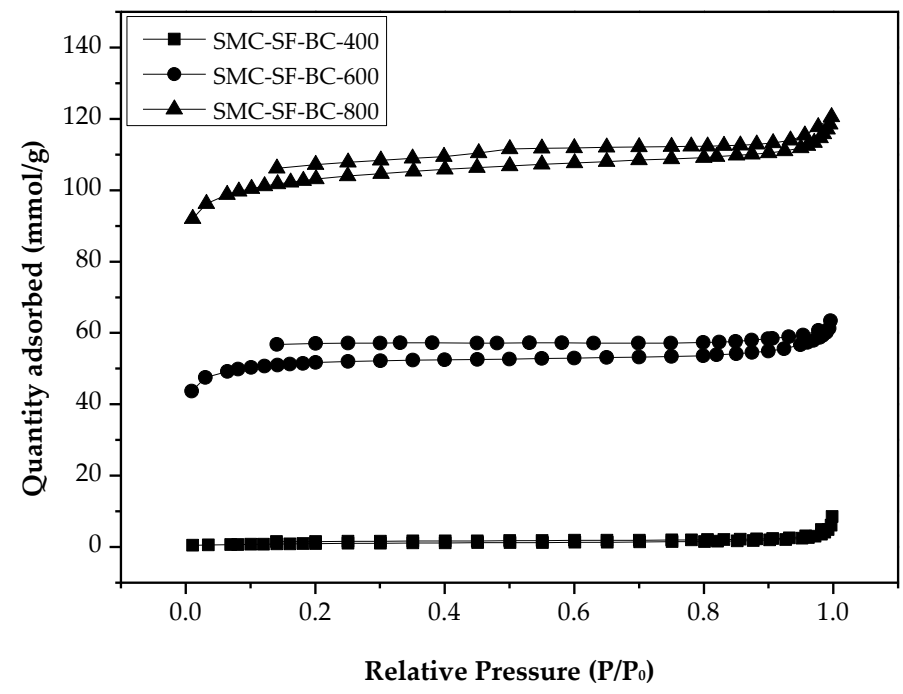

(a) SMC-SF-BC products

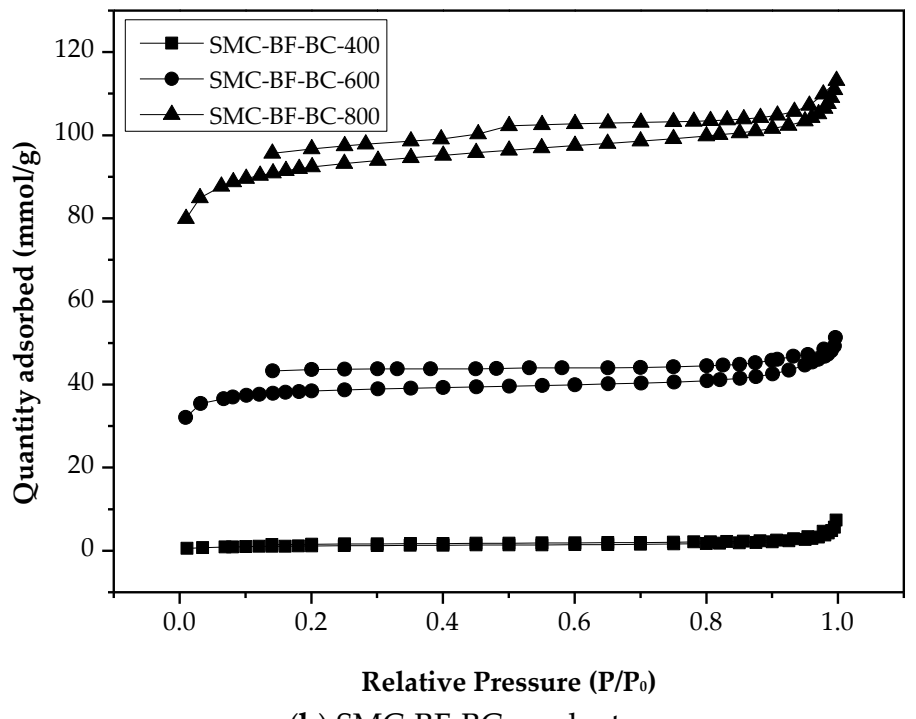

(b) SMC-BF-BC products

Figure 3. $\mathrm{N}_{2}$ adsorption-desorption isotherms of (a) SMC-SF-BC products and (b) SMC-BF-BC products.

In order to observe the porous morphology on the surface of resulting biochar products, Figures 5 and 6 showed the SEM images $(\times 1000)$ of the SMC-SF/SMC-SF -BC-800 and SMC-BF/SMC-BF-BC-800, respectively. Obviously, there are many fine pores on the rigid surface of the representative biochar products, thus exhibiting their high pore properties such as the BET surface area and total pore volume, as seen in Tables 2 and 3. Due to their highly porous structures, the SMC-based biochar products may be used as excellent adsorbents for various applications in the wastewater treatment and water retention in the soil and water environments. 


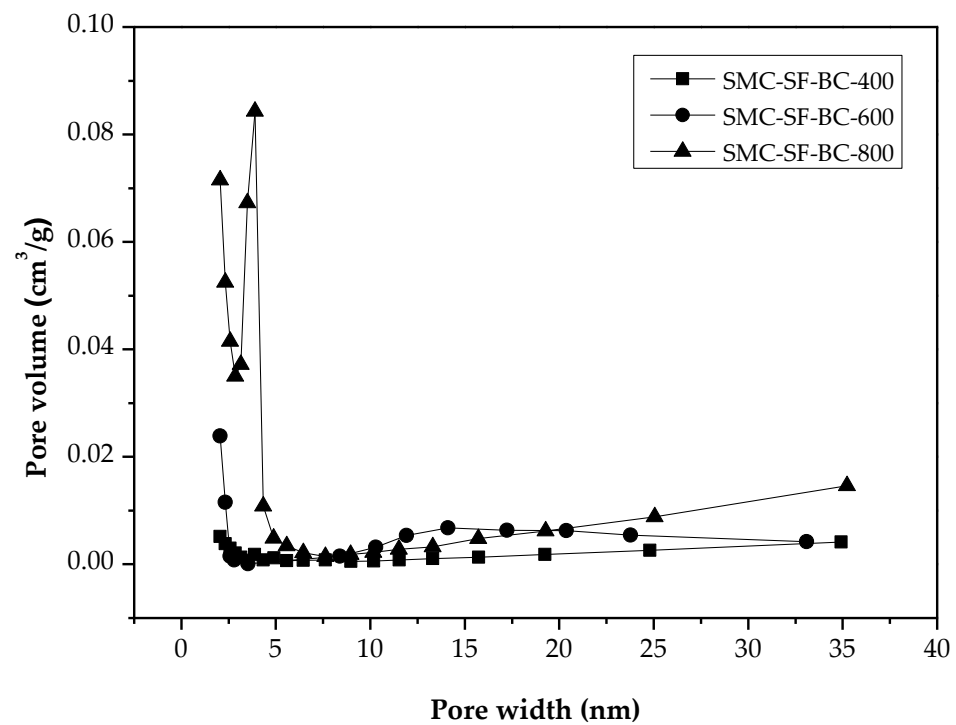

(a) SMC-SF-BC products

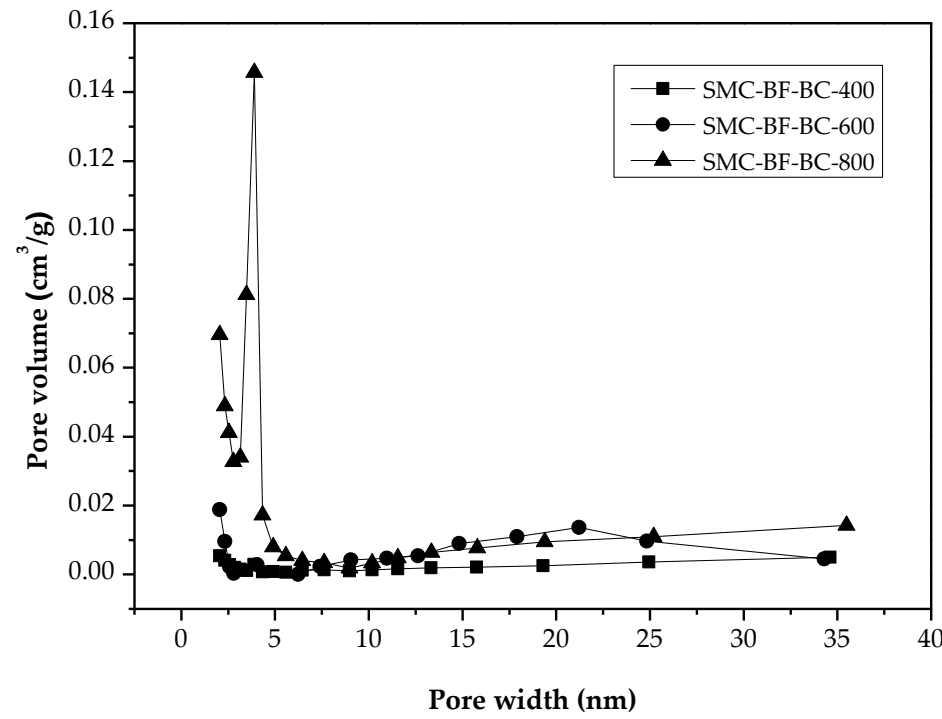

(b) SMC-BF-BC products

Figure 4. Pore size distribution curves of (a) SMC-SF-BC products and (b) SMC-BF-BC products.

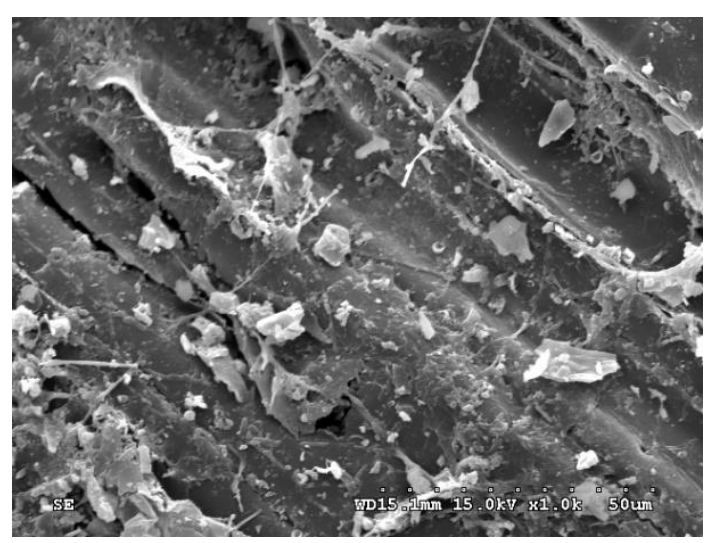

(a)

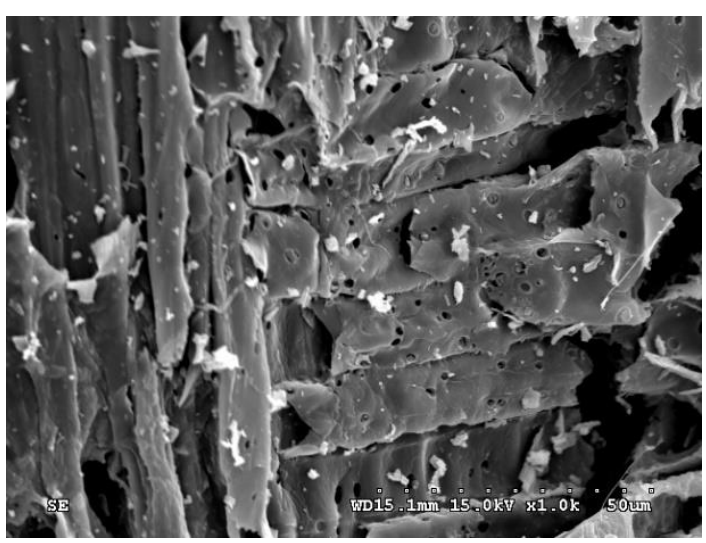

(b)

Figure 5. SEM images $(\times 1000$, right) of the biochar products for (a) SMC-SF and (b) SMC-SF-BC- 800 . 


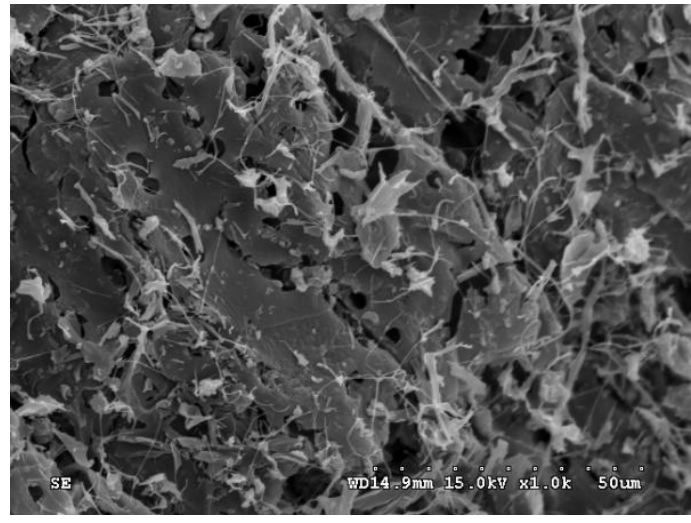

(a)

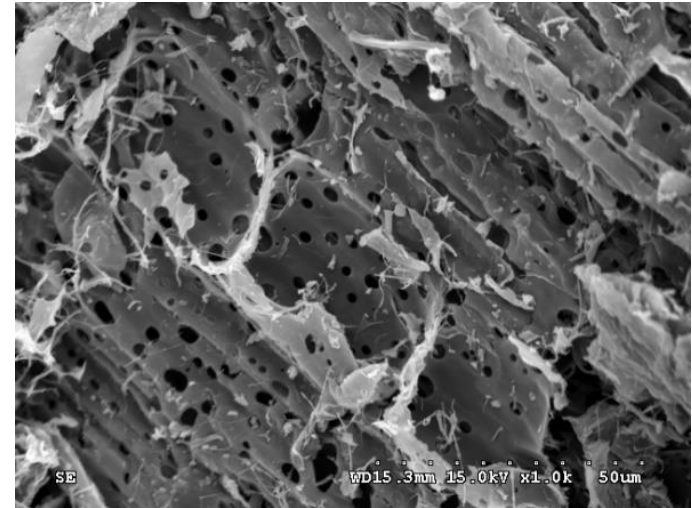

(b)

Figure 6. SEM images ( $\times 1000$, right) of the biochar products for (a) SMC-BF and (b) SMC-BF-BC-800.

\subsection{Chemical Characterization of Resulting Biochar}

The chemical characterization of resulting biochar was highly dependent on its feedstock and preparation conditions. In this work, the EDS system was adopted to semiquantify elemental compositions on the surface of the resulting biochar products [33]. Figure 7 showed the EDS spectra of the representative products (i.e., SMC-SF-BC-800 and SMC-BF-BC-800), indicating the contents of carbon $(\mathrm{C})$, oxygen $(\mathrm{O})$, magnesium $(\mathrm{Mg})$, potassium $(\mathrm{K})$ and calcium $(\mathrm{Ca})$. The difference between their elemental compositions of the resulting biochar products also showed to be small in the resulting biochar products, which could be attributed to their similar thermochemical properties (Table 1). The high content of $C$ present in the SMC-based biochar should be original from its starting feedstock and pyrolysis at high temperature $\left(800{ }^{\circ} \mathrm{C}\right)$. The carbon element was primarily stored in condensed aromatic rings [34]. In addition, it showed the high content of oxygen on the biochar surface, causing its tendency toward hydrophilicity and acidity due to more oxygencontaining complexes [35]. This polar nature was further elucidated by the FTIR spectra. Figure 8 showed the FTIR spectra of SMC-SF-BC-800 and SMC-BF-BC-800. These peaks at about $3450,2360,1640,1380$ and $1110 \mathrm{~cm}^{-1}$ could be assigned with oxygen-containing functional groups (i.e., $\mathrm{O}-\mathrm{H}, \mathrm{C}=\mathrm{O}, \mathrm{C}-\mathrm{O}$ ) [36,37].

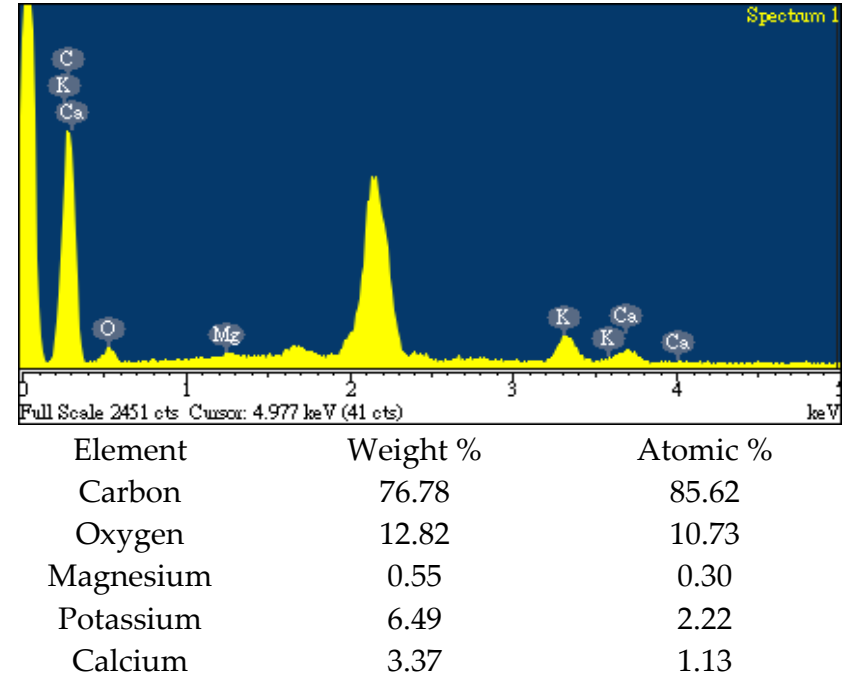

(a)

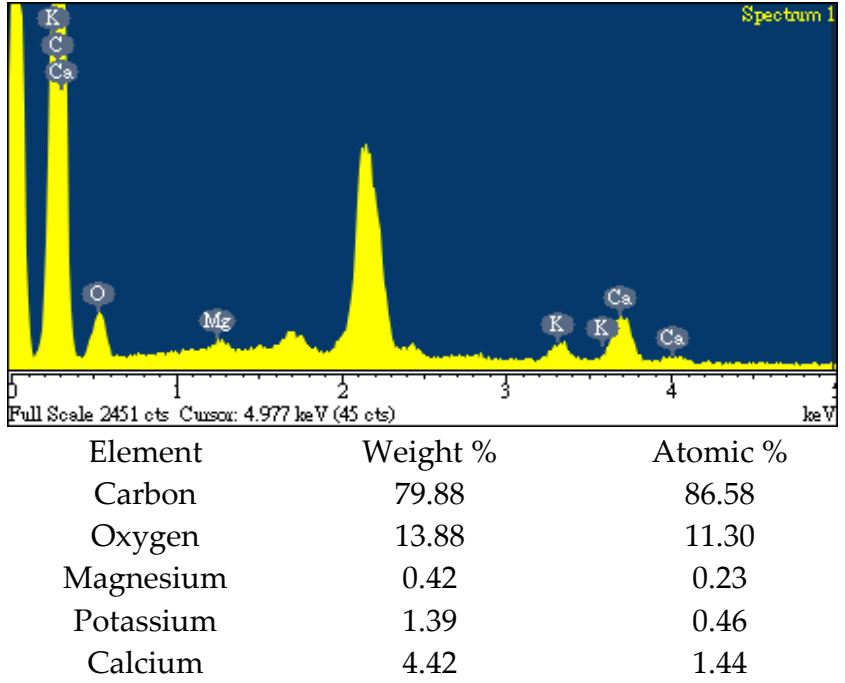

(b)

Figure 7. EDS spectra of the biochar products for (a) SMC-SF-BC-800 and (b) SMC-BF-BC-800. 


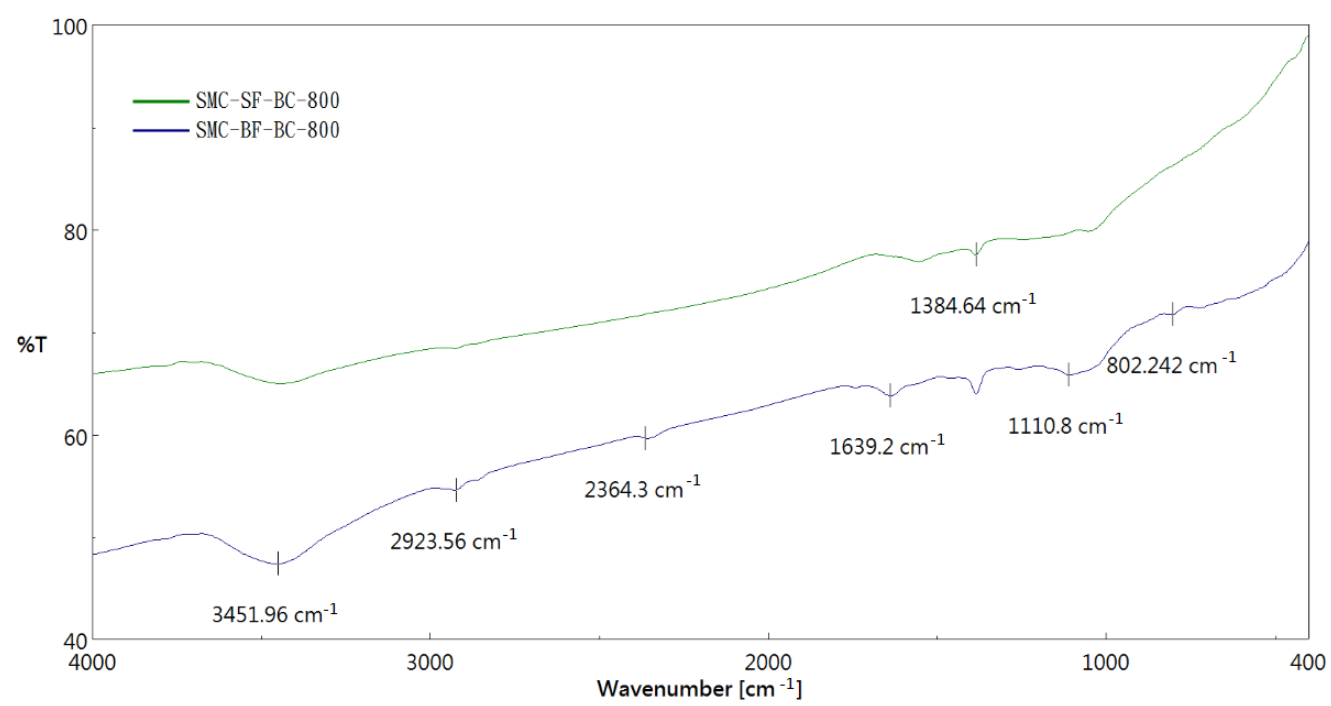

Figure 8. FTIR spectra of the biochar products (BC-SMC-SF-800 and BC-SMC-BF-800).

\section{Conclusions}

In the present study, a series of biochar products were prepared from the spent mushroom composts (SMC, including shiitake fungus -SF and black fungus - $\mathrm{BF}$ ) at various pyrolysis temperatures (i.e., 400, 600 and $800{ }^{\circ} \mathrm{C}$ ). Obviously, these SMC samples had relatively high calorific values $(>20 \mathrm{MJ} / \mathrm{kg})$, carbon contents $(45.3 \mathrm{wt} \%)$, combustible values (76-77 $\mathrm{wt} \%$ ) and low ash contents ( $3.5 \mathrm{wt} \%)$, indicating that they could be excellent precursor for producing biochar materials. The pore properties (i.e., surface area and pore volume) of the resulting biochar products were positively related to the pyrolysis temperature range (i.e., $400-800{ }^{\circ} \mathrm{C}$ ). The values of the maximal BET surface area for the resulting biochar products produced at $800{ }^{\circ} \mathrm{C}$ (i.e., SMC-SF-BC- 800 and SMC-BF-BC-800) were obtained at 312.5 and $280.9 \mathrm{~m}^{2} / \mathrm{g}$, respectively. Based on the spectroscopic peaks of the EDS and FTIR, the highly porous biochar products had plentiful oxygen-containing functional groups on the surface, which could be excellent carbon materials in the water/wastewater treatment and soil amendment due to their polar nature (i.e., hydrophilicity and acidity).

Author Contributions: Conceptualization, W.-T.T. and W.-S.C.; methodology, Y.-Q.L. and C.-H.T.; validation, Y.-Q.L.; data curation, Y.-Q.L.; formal analysis, Y.-Q.L.; resources, Y.-T.C.; writing—original draft preparation, W.-T.T.; writing — review and editing, W.-T.T. and W.-S.C.; supervision, W.-T.T. All authors have read and agreed to the published version of the manuscript.

Funding: This research was funded by the Ministry of Science and Technology (Taiwan), grant number MOST 107-2218-E-224-004.

Institutional Review Board Statement: Not applicable.

Informed Consent Statement: Not applicable.

Data Availability Statement: Not applicable.

Acknowledgments: The authors express sincere appreciation to the Instrument Center of National Pingtung University of Science and Technology for the assistance in the scanning electron microscope (SEM)/energy dispersive X-ray spectroscopy (EDS) analysis.

Conflicts of Interest: The authors declare no conflict of interest.

\section{References}

1. Grimm, D.; Kuenz, A.; Rahmann, G. Integration of mushroom production into circular food chains. Org. Agric. 2021, 11, 309-317. [CrossRef]

2. Leong, Y.K.; Ma, T.W.; Chang, J.S.; Yang, F.C. Recent advances and future directions on the valorization of spent mushroom substrate (SMS): A review. Bioresour. Technol. 2021, 344, 126157. [CrossRef] 
3. Zhang, G.S.; Liu, N.; Luo, Y.; Zhang, H.B.; Su, L.; Oh, K.; Cheng, H.Y. Efficient removal of Cu(II), Zn(II), and Cd(II) from aqueous solutions by a mineral-rich biochar derived from a spent mushroom (Agaricus bisporus) substrate. Materials 2021, 14, 35. [CrossRef]

4. Agricultural Statistics (Council of Agriculture, Taiwan). Available online: https://agrstat.coa.gov.tw/sdweb/public/common/ Download.aspx (accessed on 1 December 2021).

5. Wu, C.Y.; Liang, C.H.; Liang, Z.C. Evaluation of using spent mushroom sawdust wastes for cultivation of Auricularia polytricha. Agronomy 2020, 10, 1892. [CrossRef]

6. Antunes, F.; Marcal, S.; Taofiq, O.; Morais, A.M.M.B.; Freitas, A.C.; Ferreira, I.C.F.R.; Pintado, M. Valorization of mushroom by-products as a source of value-added compounds and potential applications. Molecules 2021, 25, 2672. [CrossRef]

7. Umor, N.A.; Ismail, S.; Abdullah, S.; Huzaifah, M.H.R.; Huzir, N.M.; Mahmood, N.A.N.; Zahrim, A.Y. Zero waste management of spent mushroom compost. J. Mater. Cycles Waste Manag. 2021, 23, 1726-1736. [CrossRef]

8. Basu, P. Biomass Gasification, Pyrolysis and Torrefaction, 2nd ed.; Academic Press: London, UK, 2013.

9. Lehmann, J.; Joseph, S. Biochar for environmental management: An introduction. In Biochar for Environmental Management, 2nd ed.; Lehmann, J., Joseph, S., Eds.; Routledge: New York, NY, USA, 2015; pp. 1-13.

10. Ma, Y.; Wang, Q.; Sun, X.; Wang, X.; Su, W.; Song, N. A study on recycling of spent mushroom substrate to prepare chars and activated carbon. BioResources 2014, 9, 3939-3954. [CrossRef]

11. Atallah, E.; Zeaiter, J.; Ahmad, M.N.; Leahy, J.J.; Kwapinski, W. Hydrothermal carbonization of spent mushroom compost waste compared against torrefaction and pyrolysis. Fuel Process. Technol. 2021, 216, 10679. [CrossRef]

12. Chen, G.J.; Peng, C.Y.; Fang, J.Y.; Dong, Y.Y.; Zhu, X.H.; Cai, H.M. Biosorption of fluoride from drinking water using spent mushroom compost biochar coated with aluminum hydroxide. Desalin. Water Treat. 2016, 57, 12385-12395. [CrossRef]

13. Abdallah, M.M.; Ahmad, M.N.; Walker, G.; Leahy, J.J.; Kwapinski, W. Batch and continuous systems for Zn, Cu, and Pb metal ions adsorption on spent mushroom compost biochar. Ind. Eng. Chem. Res. 2019, 58, 7296-7307. [CrossRef]

14. Wu, Q.; Xian, Y.; He, Z.; Zhang, Q.; Wu, J.; Yang, G.; Zhang, X.; Qi, H.; Ma, J.; Xiao, Y.; et al. Adsorption characteristics of Pb(II) using biochar derived from spent mushroom substrate. Sci. Rep. 2019, 9, 15999. [CrossRef] [PubMed]

15. Zhao, Z.; Ibrahim, M.M.; Wang, X.; Xing, S.; Heiling, M.; Hood-Nowotny, R.; Tong, C.; Mao, Y. Properties of biochar derived from spent mushroom substrates. BioResources 2019, 14, 5254-5277.

16. Chang, J.; Zhang, H.; Cheng, Y.; Yan, Y.; Chang, M.; Cao, Y.; Huang, F.; Zhang, G.; Yan, M. Spent Ganoderma lucidum substrate derived biochar as a new bio-adsorbent for $\mathrm{Pb}^{2+} / \mathrm{Cd}^{2+}$ removal in water. Chemosphere 2020, 241, 125121. [CrossRef]

17. Jin, Y.; Zhang, M.; Jin, Z.; Wang, G.; Li, R.; Zhang, X.; Liu, X.; Qu, J.; Wang, H. Characterization of biochars derived from various spent mushroom substrates and evaluation of their adsorption performance of $\mathrm{Cu}(\mathrm{II})$ ions from aqueous solution. Environ. Res. 2021, 196, 110323. [CrossRef]

18. Sewu, D.D.; Jung, H.; Kim, S.S.; Lee, D.S.; Woo, S.H. Decolorization of cationic and anionic dye-laden wastewater by steamactivated biochar produced at an industrial-scale from spent mushroom substrate. Bioresour. Technol. 2019, 277, 77-86. [CrossRef]

19. Su, L.; Zhang, H.; Oh, K.; Liu, N.; Luo, Y.; Cheng, H.; Zhang, G.; He, X. Activated biochar derived from spent Auricularia auricula substrate for the efficient adsorption of cationic azo dyes from single and binary adsorptive systems. Water Sci. Technol. 2021, 84, 101-121. [CrossRef] [PubMed]

20. Chang, K.L.; Chen, X.M.; Sun, J.; Liu, J.Y.; Sun, S.Y.; Yang, Z.Y.; Wang, Y. Spent mushroom substrate biochar as a potential amendment in pig manure and rice straw composting processes. Environ. Technol. 2017, 38, 1765-1769. [CrossRef]

21. Halim, S.F.; Yong, S.K.; Tay, C.C. Ammonia nitrogen adsorption using spent mushroom substrate biochar (SMSB). Pertanika J. Sci. Technol. 2017, 25, 9-20.

22. Lin, J.C.; Cheng, A.C.; Shiu, Y.L.; Wong, Y.C.; Yeh, S.P.; Simangunsong, T.; Liu, C.H. Using the biochar produced from spend mushroom substrate to improve the environmental condition of aquaculture pond. Aquac. Res. 2021, 52, 3532-3539. [CrossRef]

23. Lou, Z.M.; Sun, Y.; Bian, S.P.; Baig, S.A.; Hu, B.L.; Xu, X.H. Nutrient conservation during spent mushroom compost application using spent mushroom substrate derived biochar. Chemosphere 2017, 169, 23-31. [CrossRef]

24. Deng, B.; Shi, Y.; Zhang, L.; Fang, H.; Gao, Y.; Luo, L.; Feng, W.; Hu, X.; Wan, S.; Huang, W.; et al. Effects of spent mushroom substrate-derived biochar on soil $\mathrm{CO}_{2}$ and $\mathrm{N}_{2} \mathrm{O}$ emissions depend on pyrolysis temperature. Chemosphere 2020, $246,125608$. [CrossRef] [PubMed]

25. Xu, X.T.; Yuan, X.; Zhang, Q.; Wei, Q.X.; Liu, X.J.; Deng, W.P.; Wang, J.W.; Yang, W.T.; Deng, B.L.; Zhang, L. Biochar derived from spent mushroom substrate reduced $\mathrm{N}_{2} \mathrm{O}$ emissions with lower water content but increased $\mathrm{CH}_{4}$ emissions under flooded condition from fertilized soils in Camellia oleifera plantations. Chemosphere 2022, 287, 132110. [CrossRef] [PubMed]

26. Alves, L.S.; Moreira, B.R.A.; Viana, R.S.; Pardo-Gimenez, A.; Dias, E.S.; Noble, R.; Zied, D.C. Recycling spent mushroom substrate into fuel pellets for low-emission bioenergy producing systems. J. Clean. Prod. 2021, 313, 127875. [CrossRef]

27. Keiluweit, M.; Nico, P.S.; Johnson, M.G.; Kleber, M. Dynamic molecular structure of plant biomass-derived black carbon (biochar). Environ. Sci Technol. 2010, 44, 1247-1253. [CrossRef] [PubMed]

28. Tsai, C.H.; Tsai, W.T.; Liu, S.C.; Lin, Y.Q. Thermochemical characterization of biochar from cocoa pod husk prepared at low pyrolysis temperature. Biomass Convers. Biorefin. 2018, 8, 237-243. [CrossRef]

29. Tsai, W.T.; Jiang, T.J.; Lin, Y.Q.; Chang, H.L.; Tsai, C.H. Preparation of porous biochar from soapberry pericarp at severe carbonization conditions. Fermentation 2021, 7, 228. [CrossRef]

30. Lowell, S.; Shields, J.E.; Thomas, M.A.; Thommes, M. Characterization of Porous Solids and Powders: Surface Area, Pore Size and Density; Springer: Dordrecht, The Netherlands, 2006. 
31. Jenkins, B.M.; Baxter, L.L.; Miles, T.R., Jr.; Miles, T.R. Combustion properties of biomass. Fuel Process. Technol. 1998, 54, 17-46. [CrossRef]

32. Masek, O.; Johnston, C.T. Thermal analysis for biochar characterisation. In Biochar: A Guide to Analytical Methods; Singh, B., Camps-Arbestain, M., Lehmann, J., Eds.; CRC Press: Boca Raton, FL, USA, 2017; pp. 283-293.

33. Steiner, C. Considerations in biochar characterization. In Agricultural and Environmental Applications of Biochar: Advances and Barriers; Guo, M., He, Z., Uchimiya, S.M., Eds.; Soil Science Society of America: Madison, WI, USA, 2016; pp. 87-100.

34. Mukome, F.N.D.; Parikh, S.J. Chemical, physical, and surface characterization of biochar. In Biochar: Production, Characterization, and Applications; Ok, Y.S., Uchimiya, S.M., Chang, S.X., Bolan, N., Eds.; CRC Press: Boca Raton, FL, USA, 2016 ; pp. 67-96.

35. Suzuki, M. Adsorption Engineering; Elsevier: Amsterdam, The Netherlands, 1990.

36. Kleber, M.; Hockaday, W.; Nico, P.S. Characteristics of biochar: Macro-molecular properties. In Biochar for Environmental Management, 2nd ed.; Lehmann, J., Joseph, S., Eds.; Routledge: New York, NY, USA, 2015; pp. 111-137.

37. Johnston, C.T. Biochar analysis by Fourier-transform infra-red spectroscopy. In Biochar: A Guide to Analytical Methods; Singh, B., Camps-Arbestain, M., Lehmann, J., Eds.; CRC Press: Boca Raton, FL, USA, 2017; pp. 199-213. 